\title{
Knowledge Management Practices and Organizational Performance in Malaysia Government Institution
}

\author{
Norliya Ahmad Kassim, Mohammad Fazli Baharuddin, Zuhaini Abdul Samad \\ Faculty of Information Management, \\ Universiti Teknologi MARA (UiTM), \\ Shah Alam, Selangor
}

\begin{abstract}
Knowledge management (KM) is the process of managing and empowering knowledge assets optimally for organizational excellence. The purpose of this study is to investigate the practice of KM and organizational performance at one leading organization in implementing modernization strategies for Malaysian public services. In this study, there are four factors of KM practices namely; culture, structure, people and technology, which were based on the literature survey. A questionnaire was used as the main instrument in gathering data, and a total of 82 respondents were involved in this survey. Descriptive statistics using mean and standard deviation were performed to analyze the data. The results of the study revealed that information technology infrastructure factor scored the highest mean and followed by cultural issues, structural issues and people (human resource) which are all factors that scores at medium high level $($ mean $=3.68$ to 3.39). The result also showed that the level of organizational performance is at medium high level in the organization, with an overall mean score of 3.59. This study will provide some worthy thoughts of how organizations should organize to manage the competitive knowledge to ensure organizational effectiveness and performance. The results may also be used as a stepping stone for further empirical research on KM Practices in the public sector to enhance the initiatives within departments, teams or organization.
\end{abstract}

\section{Introduction}

Knowledge today is necessary and a sustainable source of competitive advantage for every organization especially in business oriented organizations. In an era characterized by rapid change and uncertainty, it is claimed that successful organizations are those that are consistently creating new knowledge, disseminate it through the organization and embodied in technologies, products and services [1]. Organizations create and define problems, develop and apply knowledge to solve problems and then further developed new knowledge through the action of problem solving. Hence, Nonaka et al. [1] argue that in many organizations, developing new knowledge is even more important than keeping track of the existing knowledge.

Government organizations are implementing Knowledge Management (KM) practices in order to improve the ways they operate and the ways they deliver public services to citizen. Improving organizational performance includes making it possible for agencies to become more innovative in carrying out their missions, while at the same time becoming more accountable to the public they serve. The organizational drive is to harness the existing knowledge in government agencies to foster creative problem solving by government workers at all levels. $\mathrm{KM}$ is a key component in this way of functioning [2].

One of the reasons why public sector at all levels may have been slowed at adopting KM for their operation is because they have to fight entrenched organization cultures in which their norm was to keep information to themselves, not to share it [3].

Esteve and Ysa [4] have identified that the differences between private and government organizations are in personnel management, decision making and information systems. According to Esteve and Ysa [4], other differences are environmental factors; in the way which organizations interact with their environments and with their stakeholders, and also in organizational structures and processes. Public organizations have less interaction with the market, they are not as influenced by rewards and punishments associated with market control. Therefore, public sector organizations are more constrained in their choices of procedures and perform activities that are mandated by political forces.

Technology has made it possible for $\mathrm{KM}$ to evolve into what it has become today; a key management tool that is necessary for agencies and institutions to function and flourish in today's knowledge economy. Administrators and managers agree that KM's blend of technology, people, culture and processes holds key to organizational improvement [5]. Moreover, government agencies had begun to adopt the KM practices which had been adopted by knowledge industries. Effective KM will cause fewer errors, less work, more independence in 
time and space for knowledge workers, better decisions, improved customers relations, improved services and improved profitability. The recent interest in $\mathrm{KM}$ is purposed to increase both innovation and responsiveness at all levels of government agencies.

Therefore, it is vital for an organization to understand the concept of KM when starting $\mathrm{KM}$ in order to succeed. Thus, Chong and Pandya (2003) suggested that the concept of KM needs to be better understood by everyone in order for the organization to be conducive to KM practices. The main aim of the study is to investigate the current level of $\mathrm{KM}$ practices and the organizational performance in one leading organization in implementing modernization strategies for public services in Malaysia.

\section{Literature Review}

According to Drucker [6], KM is an organization's capability to combine the culture, context and infrastructures of the organization to deliver high-value information ready to be applied to decision-making and service delivery with the aim to improve performance. He mentioned that: "concepts and practices evolved through the 1990s as management in the post-industrial era not only realized that knowledge was perhaps the critical resources, rather than land, machines, or capital [6].

Knowledge and management of knowledge appear to be regarded as increasingly important features for organizational survival [7]. In addition, knowledge is fundamental factor, whose successful application helps organizations deliver creative products and services. Today organizations are fundamentally different as compared to organizations that existed in one or two decades ago in terms of their functions, structures and management styles. $\mathrm{Yu}$ [8] pointed out that organizations put more emphasis on understanding, adapting and managing changes and competing on the basis of capturing and utilizing knowledge to better serve their markets.

\subsection{KM Practices}

The KM practices have given a significant impact on organizational performance. The study conducted by Fakhar et al. [9] found that KM practices appear to be a very important element for public sector to be competitive and to ensure its survival. Organizations that encourage and reward the sharing knowledge, have earned better performance of profitability, employee retention, customer satisfaction, product innovation and others.

Organizations have realized that knowledge is power - but only if it is readily accessible, organized, analyzed and displayed to solve the needs of users. Nowadays, organizations have to compete for their survival. Therefore, many organizations are operating in the global context, which poses more strategic challenges [10]. In order to stay competitive and survive, organizations are establishing their own KM systems. Technologies such as KMS allow organizations to gain vast amounts of business intelligence. KMS is a single, server-based repository that allows centralized analysis, security, and control over knowledge which designed for a strategic business unit or a department that it is a lower-cost version [11]. When KM started, the focus was purely internal to the organization and the application of technology within the scope to include learning organizations and the information profession to cover knowledge beyond and outside the organization [10].

The KM systems that are set up in organizations promote an organization-wide knowledge sharing culture. Collaboration among various units of the organization in a synergic way will increase the trust and work morale of staff resulting in increased productivity. Also, it will cut cost and fulfill the goals and objectives of the organization effectively. Therefore, KM plays a key role in accomplishing these aspects [10].

Other than that, organizations are influenced by external economic conditions and internal politic conditions (management style). The current environment dictated increased productivity with fewer resources. In order to achieve this, knowledge in the organization needs to be managed properly. Currently, the skills of information professionals are necessary to make KM work. KM has absorbed content management, project management, competitive intelligence, environmental scanning and knowledge audit as KM is applied in those areas. A study conducted by Marques and Simon (2006) found that, firms that adopt $\mathrm{KM}$ practices obtain better results than their competitors.

\subsection{KM Practices in Malaysia}

$\mathrm{KM}$ is undoubtedly a crucial activity that needs to be effectively exercised by organizations the world over. In Malaysia, KM has been identified to be a key factor in ensuring organizational success. Prior studies have highlighted the importance and benefits to local organizations [12].

In order for organizations to remain competitive and for Malaysia to effectively compete for foreign direct investment, there is a need for a smooth transition from a labour and technology intensive economy to a knowledge-based economy [8]. Yu [8] stressed the need for many factors to allow this smooth transition, one of which is the need for knowledge management practices adopted by organizations in the country to be aligned with the overall business environment in which they operate in. A thorough examination of $\mathrm{KM}$ practices in Malaysia is required to ensure the competitive 
advantage of knowledge and its manipulation [8] [13].

Understanding KM within the Malaysian context is difficult as there have been very little published work on it. There are several causes that influence the implementation of $\mathrm{KM}$ practices in Malaysia. According to Goh [14], the primary challenge faced by organizations in Malaysia is changing the employees' behavior and practices. Organizations in Malaysia tend to be highly bureaucratic and have a centralized decision-making structure with lower levels of KM applications and system in place [11].

\subsection{KM Practices in Malaysian Public Sector}

The term 'Public Sector' refers to the functioning agencies and units at the federal, state, county, municipal and local level of government. The sector includes all agencies, government corporations, the military and departments, agencies and miscellaneous units that perform some form of public service [15].

Organizations in Malaysia (public and private) have yet to manage their information (the basis of knowledge) in order to be a knowledge-based society. There are agencies that claimed to be practicing knowledge sharing, but activities are essentially based on traditional ways of communicating information such as bulletins, notice boards and face-to-face meetings [16].

A study conducted by Syed-Ikhsan and Rowland [17] examined the availability of a KM strategy in a public organization in Malaysia, and found that employees believed that the organization should have a well-defined KM strategy across the organization and they could gain a lot of benefits from managing knowledge. They concluded that KM as a practice could be the most influential strategy in managing knowledge in public organizations in Malaysia in the near future.

The main reasons why public organizations in Malaysia will be successful in managing knowledge is the government's commitment in moving towards a K-economy. The K-based Economy Master Plan (KEMP) introduced at the end of the year 2002, proved that the government is very serious in transforming Malaysia from the P-based economy (P-economy) to K-based economy (K-economy) [17].

\subsection{Organization Performance}

Organizational performance can be thought of as the output of a process that encourages creativity [18]. Thus, improvements of creativity might lead to better organizational performance. KM has become increasingly important in today's highly competitive business environment. Knowledge assets of organizations have played a crucial in this shift and are becoming increasingly more important to them these days [19]. This is because the knowledge assets of an organization are the key to innovation and differentiation which are undoubtedly engines for competitive advantage [19].

Exploratory studies on KM outcomes in Malaysia indicate that the perceived benefits include better decision-making, better understanding of customers, improved skill base, better quality and efficiency, better outputs and innovation [20]. In view of the importance of $\mathrm{KM}$ to organizations these days, a study of the key outcomes of KM shall be examined to allow for a better understanding of the need for effective KM. These include achieving organizational efficiency, competitive advantage, maximizing organizational potential and better management of knowledge assets.

\subsection{Conceptual Framework of KM Practices and Organizational Performance}

The proposed framework for this study consists of $\mathrm{KM}$ factor as independent variables and $\mathrm{KM}$ outcomes as dependent variables. KM factors are the organizational mechanism for fostering knowledge consistently which stimulates knowledge creation, protects knowledge and facilitates knowledge sharing within an organization [21].

In this study, there are four main elements of KM factors which are; culture, structure, people and technology, which was based on the literature survey. Organizational performance describes the degree to which the organization achieves its stated goals and objectives [21].The elements of organizational performance for this study are organizational efficiency, competitive advantage, maximizing organizational potential and managing knowledge assets. The framework of this study is shown in Figure 1.

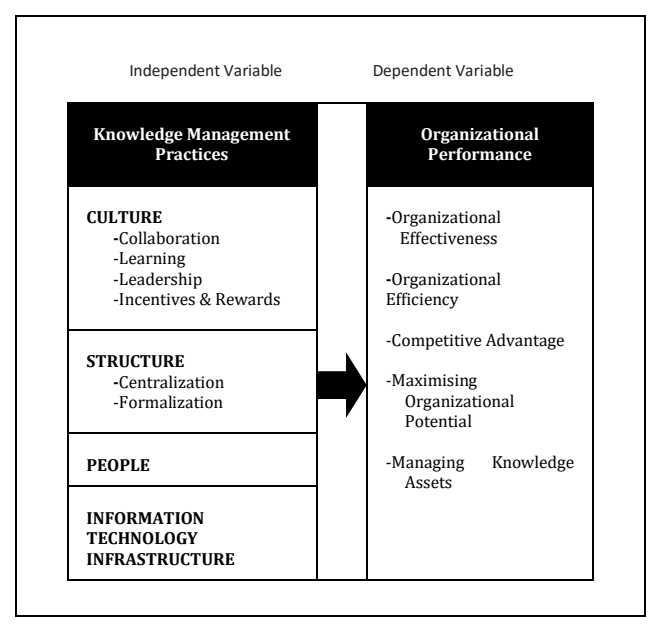

Figure 1. Conceptual Framework of KM Practices and Organizational Performance 


\section{Research Methodology}

The proposed framework for this study consists of $\mathrm{KM}$ factor as independent variables and $\mathrm{KM}$ outcomes as dependent variables. KM factors are the organizational

This study uses a survey method whereby a questionnaire was developed as the main instrument in gathering data. In this study, the target population consists of the entire staffs at every levels of the organization and used simple random sampling. A total of 175 questionnaires were distributed, however only 82 questionnaires were returned, representing a $48 \%$ response rate.

In this study, the researcher used nominal scale and open ended questions in the demographic section. Apart from that, the researcher used questions based on the level of measurement which is using Likert response scale of 1 to 5. The choices range from 1: Very Low to 5: Very High. The questionnaire was adopted with minimal modifications.

\section{Findings}

\subsection{Demographic Profile}

In this study, a total of 170 questionnaires were distributed randomly to staff in the organization, however only 82 questionnaires were returned, representing a $48 \%$ response rate. Slightly more than half $(50$ or $61.0 \%)$ of the respondents are female while $32(39.0 \%)$ are male. Majority (34 or $41.5 \%)$ of the respondents are between 31 - 40 years old, 32 $(39.0 \%)$ of the respondents are less than 30 years old, $8(9.8 \%)$ of them are between $41-50$ years old and $8(9.8 \%)$ are above 50 years old. For the level of education, slightly more than half ( 42 or $51.2 \%$ ) of the respondents have Bachelor's degree, while 12 or $14.6 \%$ of the respondents have Master's degree and Diploma respectively. Only 2 or $2.4 \%$ have Doctor of Philosophy while $14(17.1 \%)$ are others. Majority (62 or $75.6 \%$ ) of the respondents has below than 10 years of working experience with MAMPU. This is followed by 12 or $14.6 \%$ respondents has $11-20$ years of working experience and $6(7.3 \%)$ has above 30 years of working experience. Only $2(2.4 \%)$ has worked for 21-30 years at MAMPU.

\subsection{KM Awareness}

Table 1 shows the results regarding the respondents' awareness of KM practices in the organization. Majority ( 80 or $97.6 \%$ ) of the respondents are aware that it is important to have a KM strategy in the organization, that it is necessary to have a chief knowledge officer to be responsible to manage knowledge, and knowledge / information that is created and stored in electronic documentation which can be easily accessed, shared and transferred respectively.

Majority (74 or 90\%) of the respondents are aware that the organization has a written KM strategy, and that knowledge / information from individuals can be shared and transferred through formal discussions/meetings without difficulties respectively.

Also a large proportion ( 72 or $87.8 \%$ ) of the respondents is aware that technology is the most important element to develop and gain knowledge. More than three-quarter (68 or $83 \%$ ) of the respondents are aware that knowledge / information from individuals can be shared and transferred through formal discussions/meetings without difficulties.

More than half (50 or $60.98 \%$ ) are aware that knowledge/ information that is created and stored in paper documentation can be easily accessed, shared and transferred.

Table 1. Awareness on KM Practices

\begin{tabular}{|c|c|c|c|c|c|}
\hline No. & Statements & Yes & $\begin{array}{c}\text { Percent } \\
(\%)\end{array}$ & No & $\begin{array}{c}\text { Percent } \\
(\%)\end{array}$ \\
\hline 1. & $\begin{array}{l}\text { Does your Organization have a } \\
\text { written Knowledge } \\
\text { Management strategy? }\end{array}$ & 74 & 90.24 & 8 & 9.76 \\
\hline 2. & $\begin{array}{l}\text { Do you think it is important to } \\
\text { have a Knowledge } \\
\text { Management strategy in your } \\
\text { Organization? }\end{array}$ & 80 & 97.56 & 2 & 2.44 \\
\hline 3. & $\begin{array}{l}\text { Do you think it is necessary to } \\
\text { have a chief knowledge officer } \\
\text { to be responsible to manage } \\
\text { knowledge in your } \\
\text { Organization? }\end{array}$ & 80 & 97.56 & 2 & 2.44 \\
\hline 4. & $\begin{array}{l}\text { Do you think that technology } \\
\text { is the most important element } \\
\text { to develop and gain } \\
\text { knowledge? }\end{array}$ & 72 & 87.80 & 10 & 12.20 \\
\hline 5. & $\begin{array}{l}\text { Knowledge/Information that is } \\
\text { created and stored in paper } \\
\text { documentation can be easily } \\
\text { accessed, shared and } \\
\text { transferred }\end{array}$ & 50 & 60.98 & 32 & 39.02 \\
\hline 6. & $\begin{array}{l}\text { Knowledge/Information that is } \\
\text { created and stored in } \\
\text { electronic documentation can } \\
\text { be easily accessed, shared and } \\
\text { transferred }\end{array}$ & 80 & 97.56 & 2 & 2.44 \\
\hline 7. & $\begin{array}{l}\text { Knowledge/Information from } \\
\text { individuals can be shared and } \\
\text { transferred through formal } \\
\text { discussions/meetings without } \\
\text { difficulties }\end{array}$ & 68 & 82.93 & 14 & 17.07 \\
\hline 8. & $\begin{array}{l}\text { Knowledge/Information from } \\
\text { individuals can be shared and } \\
\text { transferred through informal } \\
\text { discussion without difficulties }\end{array}$ & 74 & 90.24 & 8 & 9.76 \\
\hline
\end{tabular}

For the purpose of analyzing the relationship between KM practices and organizational performance, the mean of each item and total means were described. This study has taken the position that any score in excess of 3.0, shows at medium high response with that particular statement, while overall mean score in excess of 3.0 indicates that $\mathrm{KM}$ practices and organizational performance are at medium high response. The level of KM practices 
and organizational performance can be interpreted by mean score interval [22] which is as shown in Table 2:

Table 2. Mean Score Interpretation (Nunnally \& Bernstein, 1994)

\begin{tabular}{cc}
\hline Mean Scale (Interval) & Interpretation \\
\hline $1.00-2.00$ & Low \\
$2.01-3.00$ & Medium Low \\
$3.01-4.00$ & Medium High \\
$4.01-5.00$ & High \\
\hline
\end{tabular}

Table 3 displays the descriptive statistics for the overall mean and standard deviation of the KM practices. The overall mean (3.47) describes the item level of $\mathrm{KM}$ practices in the organization. Information technology infrastructure factor (3.68) has a highest mean, followed by cultural issues (3.42), structural issues (3.40) and people (human resource) (3.39) which are all factors at medium high level. It can be concluded that the level of KM practices is at medium high level in the organization.

Table 3. Descriptive Statistics for KM Practices

\begin{tabular}{|c|c|c|}
\hline KM Practices & Mean & Std. Deviation \\
\hline Information Technology Infrastructure & 3.68 & 0.637 \\
\hline Cultural Issues & 3.42 & 0.52 \\
\hline Structural Issues & 3.40 & 0.39 \\
\hline People (Human Resource) & 3.39 & 0.64 \\
\hline OVERALL MEAN & $\mathbf{3 . 4 7}$ & $\mathbf{0 . 4 9}$ \\
\hline
\end{tabular}

Meanwhile, Table 4 displays the descriptive statistics for the overall mean and standard deviation of the organizational performance. It can be seen that, the overall mean score for organizational performance $($ mean $=3.59)$ is at medium high level. The mean score for all items are between 3.65 to 3.50 and this indicates that response is at medium high level with all the statements. Among the five statements, the mean score is highest for "KM has impact on the maximization of my organization's potential" (mean=3.65) followed by "The KM practices in my organization affect organizational performance" and "KM has impact on the management of knowledge assets in my organization" mean (3.62) and (3.62) respectively. Although the statement on "KM has impact on my organization's competitive advantage" $($ mean $=3.50)$ is the lowest, it still indicates that response is positive towards the level of organizational performance in the organization (MAMPU). It can be concluded that, level of organizational performance is at medium high level in the organization.
Table 4. Descriptive Statistics for Organizational Performance

\begin{tabular}{|c|c|c|}
\hline Organizational Performance & Mean & $\begin{array}{c}\text { Std. } \\
\text { Deviation }\end{array}$ \\
\hline $\begin{array}{l}\text { KM has impact on the maximization of } \\
\text { my organization's potential }\end{array}$ & 3.65 & 0.692 \\
\hline $\begin{array}{l}\text { The KM practices in my organization } \\
\text { affect organizational performance }\end{array}$ & 3.62 & 0.764 \\
\hline $\begin{array}{l}\text { KM has impact on the management of } \\
\text { knowledge assets in my organization }\end{array}$ & 3.62 & 0.764 \\
\hline $\begin{array}{l}\mathrm{KM} \text { has impact on my organization's } \\
\text { organizational efficiency }\end{array}$ & 3.57 & 0.738 \\
\hline $\begin{array}{l}\text { KM has impact on my organization's } \\
\text { competitive advantage }\end{array}$ & 3.50 & 0.741 \\
\hline OVERALL MEAN & 3.59 & 0.674 \\
\hline
\end{tabular}

\section{Conclusion}

This study has implications for KM practices in the context of public sector. As mentioned earlier, the role of $\mathrm{KM}$ is important in improving efficiency in decision making and service delivery in public administration. Wiig [23] suggested that KM could be considered in several areas in public administration such as enhancing decision making within public services, aiding the public to participate effectively in public decision making, building competitive societal capabilities and developing a knowledge competitive work force.

The findings from this study can be useful to enhance public policy towards effective management and implementation of KM practices. It is clear from this study that KM practices initiatives must be clearly communicated in the organization so that all public sector employees are aware on its importance and usefulness. Furthermore, this study can be attributed to lack of positive environment that enhances KM initiatives within departments, teams or organization.

$\mathrm{KM}$ is not just a $\mathrm{KM}$ process, but a process of knowledge-based management, which goal is to create tools and environments that support the process of creation, storage, dissemination and application of knowledge within an organization. Other than that, $\mathrm{KM}$ is a systematic effort to encourage and facilitate the flow of knowledge within the organization so as to accelerate the process of organizational learning. In line with the statements, public sectors can use this study to better understand the practices of $\mathrm{KM}$ in organizations, where $\mathrm{KM}$ is an approach to integrate people, processes and technology in designing, capturing and implementing intellectual infrastructure of the organization. Besides, KM also involves attitude change management, organizational behaviour and policy. It is intended that this study can help people in the organization to develop the ability to structure for the application of KM concept, even though its application is inevitably challenging but it will 
ultimately drive improved services and employment outcomes.

Finally, this study has provided previously unavailable insights into the various KM practices in an organization today and the relative benefits obtained by their implementation. The findings can help management understand how to benefit from implementing $\mathrm{KM}$ practices and justify strategic investment in KM. The insights obtained from this research will help managers to better understand how and why KM practices are effective at improving organizational performance. In summary, this research provides much-indeed insights and guidance to help the organization's managers maximize the benefit from KM initiative in future.

\section{References}

[1] I. Nonaka, R. Toyama, and N. Konno, "SECI, Ba and leadership: A unified model of dynamic knowledge creation," Long Range Planning, vol. 33, pp. 5-34, 2000.

[2] M. J. Moon, "The evolution of e-government among municipalities: Rhetoric or reality " Public Administration Review, vol. 62, pp. 424-435, 2002.

[3] S. Harris, "Critical success factors of knowledge management," Journal of Knowledge Management, vol. 12, pp. 92-111, 2001.

[4] M. Esteve and T. Ysa. (2011). Differences between the public and the private sectors? Reviewing the myth. Available:

http://www.esade.edu/public/modules.php?name=news\&id new $=676 \&$ newlang=english

[5] T. Butler, J. Feller, A. Pope, P. Barry, and C. Murphy, "Promoting knowledge sharing in government and nongovernment organizations," Electronic Journal of eGovernment, vol. 2, pp. 81-93, 2003.

[6] P. Drucker, Managing in time of great change. New York: Dutton, 1995.

[7] M. Mårtensson, "A critical review of knowledge management as a management tool" Journal of Knowledge Management, vol. 4, pp. 204-216, 2000.

[8] T.-S. Yu, "Can East Asia rise again? ," Journal of Asian Economics, vol. 13, pp. 125-146, 2003.

[9] A. Fakhar, M. Hayat, A. Shahzad, and A. Rias, "Analysis of knowledge management in the public sector of Pakistan," European Journal of Social Sciences, vol. 19, pp. 471-478, 2011.

[10] T. K. Srikantaiah and M. E. D. Koenig, Knowledge management in practice: Connections and Context. New Jersey: Information Today, Inc, 2008.

[11] M. F. Baharuddin, T. A. T. Izhar, A. N. Mohamad, and W. M. H. W. Hasnol, "A Framework based Knowledge Management System (KMS) for Dynamic
Decision-Making (DDM)," International Journal of Academic Research in Business and Social Sciences, vol. 6, pp. $287-294,2016$.

[12] B. A. Rahman, "Knowledge management initiatives: Exploratory study in Malaysia," The Journal of American Academy of Business, vol. 4, pp. 330-335, 2004.

[13] I. Nonaka and H. Takeuchi, The knowledge-creating company - How Japanese companies create the dynamics of innovation. UK: Oxford University Press, 1995.

[14] S. C. Goh, "Managing effective knowledge transfer: An integrative framework and some practice implication " Journal of Knowledge Management, vol. 6, pp. 23-30, 2002.

[15] D. E. McNabb, Knowledge management in the public sector: a blueprint for innovation in government. New York: M.E. Sharpe, Inc, 2007.

[16] K. Salleh and S. N. S. Ahmad, "Knowledge management in the local authorities - suitable platform for e-government " in Proceedings of the International Conference on Knowledge Management (ICKM), ed, 2005.

[17] S. O. S. Syed-Ikhsan and F. Rowland, "Knowledge management in a public organization: A study on the relationship between organizational elements and the performance of knowledge transfer," Journal of Knowledge Management, vol. 8, pp. 95-111, 2004.

[18] L. Prusak and T. H. Davenport, Working knowledge: How organisations manage what they know. Boston, Massachusetts: Harvard Business School Press, 1998.

[19] E. F. Yelden and J. A. Albers, "The case for knowledge management," Journal of Knowledge Management Practice, vol. 32, pp. 112-119, 2004.

[20] J. A. Kumar and L. S. Ganesh, "Research on knowledge transfer in organizations: A morphology," Journal of Knowledge Management, vol. 13, pp. 161-174, 2003.

[21] H. Lee and B. Choi, "Knowledge management enablers, processes, and organizational performance " Journal of Management Information Systems, vol. 20, pp. 179-228, 2003.

[22] J. C. Nunnally and I. H. Bernstein, Psychometric theory (3rd ed.). New York: McGraw-Hill, 1994.

[23] K. M. Wiig, "Knowledge management in public administration," Journal of Knowledge Management, vol. 6, pp. 224-239, 2002. 